\title{
Patch Testing in Nepalese Population: A Single Center Study from Kathmandu, Nepal
}

\author{
Paudel S', Pun G', Parajuli N², Paudel S S $^{3}$ Sharma $\mathbf{R}^{1}$
}

${ }^{1}$ Department of Dermatology, Civil Service Hospital, ${ }^{2}$ National Academy of Medical Sciences, ${ }^{3}$ Department of Public Health, Patan Academy of Health Sciences

\begin{abstract}
Introduction: Patch testing is a diagnostic tool used in investigation to identify specific allergens in allergic contact dermatitis ( $A C D)$. It helps find the prevalence and the trends of contact sensitization in the community.

Objective: To report the two years' patch test results from a central hospital in Kathmandu.

Materials and Methods: Consecutive consenting patients of suspected ACD were patch tested with an Indian standard Series (Systopic) from June 2014 to August 2016.

Results: Out of 141 patients tested, 89 were female (63.12\%) and 52 were male (36.88\%). Hand eczema was the commonest pattern (53 patients) followed by persistent and recurrent eczema (44 patients) and face eczema (25 patients). Fifty- five patients (39\%) had at least 1 positive allergic reaction. Among these, $16.31 \%$ were male and $22.70 \%$ were female. The most common allergen was nickel sulfate $(19.9 \%)$ followed by fragrance mix $(7.8 \%)$ and paraphenyldiamine (PPD) (6.4\%). Out of total positive cases 27 (21 females and 6 males) had shown strong positive reactions (++). The Nickel Sulfate was responsible in majority of cases (18/27 cases). Farmers had the highest (57.14\%) rate of positive allergic reactions followed by housewives (39.62\%). According to the regional eczema, patients with persistent and recurrent eczema of different parts of body had the highest rate of positive allergic reactions (47.72\%). Almost half of patient with facial eczema (40\%) had positive patch test.

Conclusion: Larger studies are required in the different parts of the country to find a more accurate data regarding the sensitization pattern in Nepalese population.
\end{abstract}

Key words: Allergens; Dermatitis, Allergic Contact; Eczema; Nickel sulfate

\section{Introduction}

$\mathrm{P}$ atch testing is a diagnostic tool used in investigation to identify specific allergens in allergic contact dermatitis ( $A C D$ ) or, in some cases, to make the diagnosis of ACD. ${ }^{1}$ The principle of patch test (PT) is that in sensitized individuals, primed antigenspecific T lymphocytes of the Th1 phenotype circulate throughout the body and are able to recreate a delayedtype hypersensitivity reaction when nonirritating concentrations of the antigen are applied to normal skin..$^{2,3}$ The procedure of patch testing is not a difficult one to perform, but the reading and interpretation of the PT and establishing their relevance to the individual cases require training and experience. Once the PT is completed, allergens are identified, and relevance has been established, educating the patient about the avoidance of exposure is critical. ${ }^{2}$

\section{Address of Correspondence:}

Dr. Sushil Paudel

Registrar

Department of Dermatology

Civil Service Hospital, Kathmandu, Nepal

E-mail: paudelsushil@gmail.com
Skin diseases are one of the common and significant causes of morbidity in Nepal. The most common skin disease was eczemas in a study conducted by Shrestha and collegues, which consists of $12.2 \%$ of all dermatological diseases (Shrestha, Gurung and Rosdahl, 2012). ${ }^{4}$ It has been found that rapid urbanization has led to exposure and subsequent sensitization of Nepalese population to many allergens. ${ }^{5}$ This has increased the importance of patch testing in Nepal as well.

\section{Submitted: $28^{\text {th }}$ October 2018}

Accepted: $30^{\text {th }}$ January 2019

Published: $31^{\text {st }}$ March 2019

\section{How to cite this article}

Paudel S, Pun G, Parajuli N, Paudel S, Sharma R. Patch testing in Nepalese population: A single center study from Kathmandu, Nepal. Nepal Journal of Dermatology, Venereology and Leprology. 2019;17(1):12-6. doi: http://dx.doi. org/10.3126/ njdvl.v17i1.23118

\section{(c) (i)}

Licensed under CC BY 4.0 International License which permits use, distribution and reproduction in any medium, provided the original work is properly cited. 
The aim of this study is to analyze the results of patch testing with Indian Standard Series (20 allergen kit by Systopic India Ltd) and compare the results with other similar studies in other centers in Nepal and the subcontinent.

\section{Materials and Methods}

This was a hospital based retrospective analysis of the data collected from the patients who were patch tested with a clinical diagnosis of allergic contact dermatitis. The study was approved by the institutional review board. All patients who were patch tested at our center from June 2014 to August 2016 were included in this study.

Patch testing was performed using the Indian Standard Series of allergens (20 allergens) using aluminum patch test chambers mounted at the back with the help of micropore paper tape. The reading and interpretation of the results were in accordance to the International Contact Dermatitis Research Group (ICDRG) with the application of 2 days and reading at $2^{\text {nd }}$ and $4^{\text {th }}$ day. The PT results were read by the same investigator. ${ }^{6}$

Sample Size: A total of 141 of patients were included in this retrospective data analysis. All patients with clinical diagnosis of allergic contact dermatitis after getting due consent were subjected to the patch test. They were properly instructed on the procedure of patch tests. Patient privacy was maintained at utmost.

\section{Data management}

The data obtained from the proforma were collected, checked and entered in the SPSS data sheet.

\section{Results}

There were a total of 141 patients included in the study. Among these, 89 were female (63.12\%) and 52 were male (36.88\%). The majority of the patients were from the age group $20-30$ years (33.57\%) (Table 1 ). The distribution of sensitization to the allergens based on sex is summarized as table 2 and 3.
Hand eczema was the most common pattern of dermatitis for the patch test seen in 53 patients. The other common form was persistent and recurrent eczematous eruption on different parts of body other than face and palms/ sole found in 44 patients. Regional dermatitis of face, lip and ear was seen in 25 patients (Table 4).

According to the occupation, the most frequently patch tested group was housewives (53), followed by skilled labors (33), students (27), office workers (21) and farmers (7) (Table 5).

Fifty- five patients (39\%) had at least 1 positive allergic reaction. Among these, $16.31 \%$ were male and $22.70 \%$ were female.

None of patients showed positive reactions to wool, alcohol or $2 \%$ formaldehyde. In rest of the allergen there was at least one positive reaction. The most common allergen was nickel sulfate $(19.9 \%)$ followed by fragrance $\operatorname{mix}(7.8 \%)$ and paraphenyldiamine (6.4\%). These allergens were followed in order of frequency by cobalt sulfate (5\%), nitrofurazon (3.5\%), parthenium (2.8\%), colophony $(2.8 \%)$, balsam of Peru $(2.1 \%)$, potassium dichromate $(2.1 \%)$ and benzocaine (2.1\%). The reactions to other allergens were less than $2.0 \%$.

Out of total positive cases 27 ( 21 females and 6 males) had shown strong positive reactions $(++)$. The Nickel Sulfate was responsible in majority of cases (18/27 cases). Whilst, 37 cases (19 males and 18 females) had mild $(+)$ reactions in patch testing.

According to the profession, farmers had the highest $(57.14 \%)$ rate of positive allergic reactions followed by housewives (39.62\%). Male skilled labors had a slightly low rate of allergic reactions (33.33\%).

According to the regional eczema, patients with persistent and recurrent eczema of different parts of body had the highest rate of positive allergic reactions (47.72\%). Almost half of patient with facial eczema (40\%) had positive patch test.

Table 1: Frequency of positive result cases according to age group.

\begin{tabular}{|c|c|c|c|c|c|c|c|}
\hline \multirow{2}{*}{ Age in years } & \multirow{2}{*}{ Number } & \multicolumn{3}{|c|}{ Male } & \multicolumn{2}{c|}{ Female } & \multicolumn{2}{c|}{ Total } \\
\cline { 3 - 8 } & & (+ve) $\mathbf{n}$ & $\mathbf{\%}$ & (+ve) $\mathbf{n}$ & $\mathbf{\%}$ & (+ve) $\mathbf{n}$ & \% \\
\hline$<10$ & 1 & 0 & 0 & 0 & 0 & 0 & 0 \\
\hline $10-20$ & 24 & 0 & 0 & 6 & 24 & 6 & 42.55 \\
\hline $20-30$ & 47 & 9 & 19.15 & 11 & 23.4 & 20 & 82.86 \\
\hline $30-40$ & 28 & 4 & 14.29 & 8 & 28.57 & 12 & 41.46 \\
\hline$>40$ & 41 & 10 & 24.39 & 7 & 17.07 & 17 & $\mathbf{3 9 . 0 0}$ \\
\hline Total & $\mathbf{1 4 1}$ & $\mathbf{2 3}$ & $\mathbf{1 6 . 3 1}$ & $\mathbf{3 2}$ & $\mathbf{2 2 . 7 0}$ & $\mathbf{5 5}$ & \\
\hline
\end{tabular}


Paudel S, et al. Patch testing in Nepalese population

Table 2: Table showing patch test results with each reactant according to sex.

\begin{tabular}{|c|c|c|c|c|c|}
\hline \multirow{2}{*}{$\begin{array}{l}\text { Chemical (concentration \% and vehicle) } \\
\text { Vaseline } 100 \%\end{array}$} & \multicolumn{5}{|c|}{ Number of positive patch tests } \\
\hline & $\begin{array}{c}\text { Total }(\mathrm{n}=\mathbf{8 6}) \\
0\end{array}$ & \multicolumn{2}{|c|}{ Male } & \multicolumn{2}{|c|}{ Female } \\
\hline Wool alcohol & 0 & & & & \\
\hline Balsam peru & 3 & $2+$ & & $1+$ & \\
\hline Formaldehyde $2 \%$ & 0 & & & & \\
\hline Mercaptobenzothiazole & 1 & $1+$ & & & \\
\hline Potassium dichromate & 3 & $\begin{array}{l}1+ \\
2+\end{array}$ & & & \\
\hline Nickel sulphate $5 \%$ & 28 & $\begin{array}{l}1+ \\
1+\end{array}$ & $3++$ & $\begin{array}{l}1+ \\
7+\end{array}$ & $15++$ \\
\hline Cobalt sulphate $5 \%$ & 7 & $\begin{array}{l}1+ \\
4+\end{array}$ & & $1+$ & $1++$ \\
\hline Colophony $10 \%$ & 4 & & & $2+$ & $2++$ \\
\hline Epoxy resin $1 \%$ & 1 & $1+$ & & & \\
\hline Paraben mix 9\% & 1 & $1+$ & & & \\
\hline Paraphenylenediamine & 9 & $\begin{array}{l}2+ \\
1+\end{array}$ & & $\begin{array}{l}2+ \\
3+\end{array}$ & $1++$ \\
\hline Parthenium 15\% & 4 & $1+$ & $2++$ & $1+$ & \\
\hline Neomycin_sulphate $20 \%$ & 1 & $1+$ & & & \\
\hline Benzocaine $5 \%$ & 3 & & $1++$ & $\begin{array}{l}1+ \\
1+\end{array}$ & \\
\hline Chlorocreson $1 \%$ & 2 & $1+$ & & $1+$ & \\
\hline Fragrance mix $8 \%$ & 11 & $\begin{array}{l}3+ \\
2+\end{array}$ & & $\begin{array}{l}2+ \\
3+\end{array}$ & $1++$ \\
\hline Thiuram mix $1 \%$ & 2 & $1+$ & $1++$ & & \\
\hline Nitrofurazon $1 \%$ & 5 & $\begin{array}{l}1+ \\
2+\end{array}$ & & $1+$ & $1++$ \\
\hline Black rubber mix $0.6 \%$ & 1 & $1+$ & & & \\
\hline Angry back & 0 & & & & \\
\hline Total & 86 & 31 & 7 & 27 & 21 \\
\hline
\end{tabular}

Note: + definite mild,++ definite strong

Table 3: Table showing patch-test results based on sex.

\begin{tabular}{|l|c|c|c|c|c|}
\hline \multirow{2}{*}{} & \multicolumn{9}{|c|}{ Test result } & \multirow{2}{*}{ Total } \\
\cline { 2 - 5 } & \multicolumn{2}{|c|}{ Positive } & $\mathbf{n}$ & Negative & \\
\cline { 2 - 5 } & $\mathbf{n}$ & $\mathbf{\%}$ & 29 & 55.8 & 52 \\
\hline Male & 23 & 44.2 & 57 & 64 & 89 \\
\hline Female & 32 & 36 & $\mathbf{8 6}$ & $\mathbf{6 1}$ & $\mathbf{1 4 1}$ \\
\hline
\end{tabular}

Table 4: Frequency of positive result cases according to diagnosis.

\begin{tabular}{|c|c|c|c|c|c|c|}
\hline \multirow{2}{*}{ Clinical Diagnosis } & \multicolumn{2}{|c|}{ Male } & \multicolumn{2}{|c|}{ Female } & \multicolumn{2}{|c|}{ Total } \\
\hline & $\mathbf{n}$ & $\%$ & $\mathbf{n}$ & $\%$ & n & $\%$ \\
\hline Hand Eczema $(n=53)$ & 8 & 15.09 & 10 & 18.87 & 18 & 33.96 \\
\hline Face/Lip/Ear Eczema ( $n=25)$ & 1 & 4 & 9 & 36 & 10 & 40 \\
\hline Atopic Dermatitis $(n=19)$ & 3 & 15.79 & 3 & 15.79 & 6 & 31.58 \\
\hline Partly Body Eczema $(n=9)$ & 2 & 22.22 & 2 & 22.22 & 4 & 44.44 \\
\hline $\begin{array}{l}\text { ACD/ABCD }(n=35) \\
\text { (persistent and recurrent } \\
\text { eczematous eruptions) }\end{array}$ & 9 & 25.71 & 8 & 22.86 & 17 & 48.57 \\
\hline Total $(n=141)$ & 23 & 16.31 & 32 & 22.70 & 55 & 39.01 \\
\hline
\end{tabular}


Table 5: Frequency of positive result cases according to occupation.

\begin{tabular}{|l|c|c|c|c|c|c|}
\hline & \multicolumn{2}{|c|}{ Male } & \multicolumn{2}{c|}{ Female } & \multicolumn{2}{c|}{ Total } \\
\hline & $\mathbf{n}$ & $\mathbf{\%}$ & $\mathbf{n}$ & $\mathbf{\%}$ & $\mathbf{n}$ & \% \\
\hline Housewife $(\mathrm{n}=53)$ & 0 & 0 & 21 & 39.62 & 21 & 39.62 \\
\hline Farmer $(\mathrm{n}=7)$ & 4 & 57.14 & 0 & 0 & 4 & 57.14 \\
\hline officer-worker $(\mathrm{n}=21)$ & 5 & 23.81 & 3 & 14.29 & 8 & 38.1 \\
\hline skilled-labor $(\mathrm{n}=33)$ & 11 & 33.33 & 3 & 9.09 & 14 & 42.41 \\
\hline Students $(\mathrm{n}=27)$ & 3 & 11.11 & 5 & 18.52 & 8 & 29.63 \\
\hline
\end{tabular}

Table 6: Comparison of common allergens in different studies

\begin{tabular}{|c|c|c|c|c|c|c|c|}
\hline & Nepal & India ${ }^{13}$ & India ${ }^{14}$ & China $^{16}$ & |sreal ${ }^{12}$ & Europe ${ }^{15}$ & USA $^{17}$ \\
\hline Nickel sulphate & 19.9 & 31.4 & 12.9 & 22.1 & 13.9 & 17.9 & 16.7 \\
\hline Fragrance mix & 7.8 & 11.4 & 5.5 & 15.5 & 7.1 & 9.7 & 10.4 \\
\hline Phenylenediamine & 6.4 & 6.4 & 5.3 & 12.8 & 1.8 & 3.9 & 4.8 \\
\hline Cobalt sulphate/chloride & 5 & 12.1 & 5.4 & NA & 3.4 & 5.9 & 7.4 \\
\hline Nitrofurazone & 3.5 & 10.7 & 6 & NA & NA & NA & NA \\
\hline Parthenium & 2.8 & 26.4 & 14.6 & NA & NA & NA & NA \\
\hline Colophony & 2.8 & 9.3 & 5.7 & 5 & 0.8 & 4 & 2.6 \\
\hline Potassium dichromate & 2.1 & 15.7 & 11.1 & 8.9 & 3.8 & 4.6 & 4.3 \\
\hline
\end{tabular}

\section{Discussion}

In our study, fifty-five patients (39\%) out of 141 patients tested with patch test for suspected ACD showed at least 1 positive reaction. This finding was similar to a Turkish study where it was $32.3 \%$ and Isreali study where it was $43.5 \%{ }^{7,8}$ But contrary finding was found in study conducted in Nepal by Parajuli et al (2017) which showed a higher allergic reaction (54.3\%). ${ }^{5}$ The discrepancy might be due to their small sample size (35 patients). Similarly, some studies got even higher sensitization than noted by Parajuli et al; Sharma VK et al 1998 (65.5\%) and VK Sharma et al 2004 (63.6\%).5,9,10

The most common pattern was the hand eczemas, which was similar to the findings of Parajuli et al (2017), Agrup G 1969, Goh C L 1989 and Holness D L et al 1995.5,11-13 This was in contrast to Indian studies which showed air borne contact dermatitis as being the commonest type of eczema. ${ }^{10}$

Nickel was the commonest sensitizer in this study (19.9\%). Most of the Asian and European studies also reported nickel as the commonest sensitizer (Table $6)$. The pattern of sensitization is similar to the other centers in the world where nickel was the most common sensitizer. But Indian studies showed parthenium to be the most common. The next most common sensitizer in our study was fragrance mix which was similar to the studies from China, Isreal, Europe and United states. But on the contrary, fragrance mix from Indian studies was found less common. ${ }^{14}$
Sensitivity to Phenylenediamine in our study (6.4\%) was comparable to studies from other countries as well except for a Chinese study (12.8\%). Cobalt sensitivity (5\%) was similar to that of European and US studies but lower than an Indian study (12.1\%). Parthenium is not seen as much of a menace in Nepal as in India. But the rapid growth of this plant in the higher lands may invite trouble in future. Colophony was found to sensitize only female patients $(2.8 \%)$ in our study. The reason might be due to increasing use of cosmetic ranges with rosin in it. The sensitivity of the potassium dichromate $(2.1 \%)$ was found to be lower than in other studies compared to ours. The reason for this might be less construction work going on that particular period and even lower rate of seeking medical consultation with dermatologist for patch testing. Wool alcohol and formaldehyde were not found to sensitive in any of the patients. All others allergens showed less than $2 \%$ sensitivity in our study.

Use of single type of patch test kit with only 19 allergens being used. Sample size was not large enough.

\section{Conclusion}

We found that more than one third of suspected allergic cases show positive reaction to one or more of commonly used allergen series. Most common allergen being nickel (19.9\%) followed by fragrance mix and PPD. Hand eczema is most common condition subjected to patch test. We need to do patch testing 
more frequently. Feet and face dermatitis are less studied about and they need more focus. A multicentric study with larger sample size might be able to find different type of common allergens which would be useful to devise an appropriate set of patch test kit for the Nepalese population. A multi-centric study with larger sample size might be able to find different type of common allergens which would be useful to devise

\section{References}

1. Wahlberg JE. Patch testing. In: Rycroft RJG, Menne T, Frosch PJ, Lepoittevin JP, eds. Textbook of Contact Dermatitis, 3rdedn. Berlin: Springer, 2001:435-68 https://doi.org/10.1007/978-3-662-10302-9_21

2. Fonacier L. A Practical Guide to Patch Testing. J Allergy ClinImmunolPract. 2015 Oct;3(5):669-75. https://doi.org/10.1016/j.jaip.2015.05.001

3. Rustmeyer $\mathrm{T}$, van Hoogstraten IMW, von Blomberg ME, Scheper RJ. Mechanisms in allergic contact dermatitis. In: Rycroft RJG, Menne T, Frosch PJ, Lepoittevin JP, eds. Textbook of Contact Dermatitis, $3^{\text {rd }}$ edn. Berlin: Springer, 2001:11-58. https://doi.org/10.1097/01634989-20010300000034

4. Shrestha DP, Gurung D, Rosdahl I. Prevalence of skin diseases and impact on quality of life in hilly region of Nepal. Journal of Institute of Medicine. 2012;34:44-9.

5. Parajuli S, Paudel V, Paudel U, Pokhrel DB. Pattern of patch test reactivity among patients with clinical diagnosis of contact dermatitis: A hospitalbased study. Our Dermatol Online. 2017;8(4):38992. https://doi.org/10.7241/ourd.20174.111

6. Wilkinson DS, Fregert $S$, Magnusson B, Bandmann $\mathrm{HJ}$, Calnan CD, Cronin E et al. Terminology of contact dermatitis. ActaDermVenereol. 1970;50:287-92.

7. Akyol A, Boyvat A, Peksari Y, Gurgey E. Contact sensitivity to standard series allergens in 1038 patients with contact dermatitis in Turkey. Contact Dermatitis. 2005: 52: 333-7. https://doi. org/10.1111/j.0105-1873.2005.00608.x

8. Lazarov A. European standard series patch test results from a contact dermatitis clinic in Israel during the 7 year period from 1998 to 2004 . Contact Dermatitis. 2006:55:73-6. https://doi. org/10.1111/j.0105-1873.2006.00875.x

9. Sharma VK, Chakrabarti A. Common contact sensitizers in Chandigarh, India: a study of 200 patients with the European standard series. an appropriate set of patch test kit for the Nepalese population.

Acknowledgement: Support staff Ms Kumari Ghale and statistician Mr Krishna Bahadur GC for their kind help.

Financial disclosure: None

Conflict of interest to disclosure: None declared.
Contact Dermatitis 1998: 38: 127-31. https://doi. org/10.1111/j.1600-0536.1998.tb05677.x

10. Sharma VK, Sethuraman G, Garg T, Verma KK, Ramam M. Patch testing with the Indian standard series in New Delhi. Contact Dermatitis. 2004;51(5-6):319-21. https://doi.org/10.1111/ j.0105-1873.2004.0459k.x

11. Agrup G. Hand eczema and other hand dermatoses in South Sweden. Acta Dermatolvenereologica1969: 49(suppl 61):73,74,84.

12. Goh C L. An epidemiological comparison between occupational and non-occupational hand eczema. $\mathrm{Br} J$ Dermatol 1989: 120: 77-82. https://doi. org/10.1111/j.1365-2133.1989.tb07768.x

13. Holness DL, Nethercott JR, Adams RM,Belsito D, Deleo V, Emmett EA et al. Concomitant positive patch test results with standard screening tray in North America, 1985-1989. Contact Dermatitis 1995:32: 289-92. https://doi. org/10.1111/j.1600-0536.1995.tb00783.x

14. Bajaj AK, Saraswat A, Mukhija G, Rastogi S, Yadav S. Patch testing experience with 1000 patients. Indian J Dermatol Venereol Leprol. 2007;73(5):313-8. https://doi.org/10.4103/03786323.34008

15. Bruynzeel DP, Diepgen TL, Andersen KE, Brandão FM, Bruze M, Frosch PJ et al. Monitoring the European standard series in 10 centers 1996-2000. Contact Dermatitis. 2005: 53: 146-9. https://doi. org/10.1111/j.0105-1873.2005.00541.x

16. Li LF, Guo J, Wang J. Environmental contact factors in eczema and the results of patch testing Chinese patients with a modified European standard series of allergens. Contact Dermatitis. 2004: 51: 22-5. https://doi.org/10.1111/j.01051873.2004.00369.x

17. Pratt MD, Belsito DV, DeLeo VA, Fowler JF $\mathrm{Jr}$, Fransway AF, Maibach $\mathrm{HI}$ et al. North American Contact Dermatitis Group patch-test results. 2001-2002 study period. Dermatitis. 2004, 2001-02: 15: 176-83. https://doi. org/10.2310/6620.2004.04038 